\title{
An Overview of Novel Unconventional Mechanisms of Hematopoietic Development and Regulators of Hematopoiesis - a Roadmap for Future Investigations
}

\author{
Kamila Bujko ${ }^{1}$ - Monika Cymer ${ }^{2}$ - Mateusz Adamiak ${ }^{2}$ - Mariusz Z. Ratajczak ${ }^{1,2}$ (D)
}

Published online: 22 October 2019

(C) The Author(s) 2019

\begin{abstract}
Hematopoietic stem cells (HSCs) are the best-characterized stem cells in adult tissues. Nevertheless, as of today, many open questions remain. First, what is the phenotype of the most primitive "pre-HSC" able to undergo asymmetric divisions during ex vivo expansion that gives rise to HSC for all hemato-lymphopoietic lineages. Next, most routine in vitro assays designed to study HSC specification into hematopoietic progenitor cells (HPCs) for major hematopoietic lineages are based on a limited number of peptide-based growth factors and cytokines, neglecting the involvement of several other regulators that are endowed with hematopoietic activity. Examples include many hormones, such as pituitary gonadotropins, gonadal sex hormones, IGF-1, and thyroid hormones, as well as bioactive phosphosphingolipids and extracellular nucleotides (EXNs). Moreover, in addition to regulation by stromal-derived factor 1 (SDF-1), trafficking of these cells during mobilization or homing after transplantation is also regulated by bioactive phosphosphingolipids, EXNs, and three ancient proteolytic cascades, the complement cascade (ComC), the coagulation cascade (CoA), and the fibrinolytic cascade (FibC). Finally, it has emerged that bone marrow responds by "sterile inflammation" to signals sent from damaged organs and tissues, systemic stress, strenuous exercise, gut microbiota, and the administration of certain drugs. This review will address the involvement of these unconventional regulators and present a broader picture of hematopoiesis.
\end{abstract}

Keywords Hematopoietic stem cells $\cdot$ Chemokines $\cdot$ Purinergic signaling $\cdot$ Bioactive phosphosphingolipids $\cdot$ Stem cell trafficking $\cdot$ Sterile inflammation $\cdot$ Hormones $\cdot$ VSELs $\cdot$ Stem cell mobilization

\section{Introduction}

Hematopoietic stem/progenitor cells (HSPCs) are the beststudied stem cells and have been widely employed in the clinic for 50 years. In addition to bone marrow (BM) as a source of HSPCs [1], cells for transplantations are derived from mobilized peripheral blood (mPB) [2] and umbilical cord

Mariusz Z. Ratajczak

mzrata01@louisville.edu

Kamila Bujko

kamila.bujko@1ouisville.edu

Monika Cymer

Monika.Cymer@wum.edu.pl

1 Stem Cell Institute at James Graham Brown Cancer Center, University of Louisville, 500 S. Floyd Street, Rm. 107, Louisville, KY 40202, USA

2 Center for Preclinical Studies and Technology, Department of Regenerative Medicine, Medical University of Warsaw, Warsaw, Poland blood (UCB) [3]. Several in vitro and in vivo assays have been proposed to study their hematopoietic potential in experimental settings and to use as tools to help in the diagnosis of hematological disorders [4]. Nevertheless, there remain some unanswered questions in this field and some unresolved controversies.

The classical in vitro clonogenic assays for characterizing HSPC commitment to different lineages are based on the application of selected peptide-based hematopoietic growth factors (kit ligand [KL]) and cytokines (granulocyte-macrophage colony stimulating factor [GM-CSF], granulocyte colonystimulating factor [G-CSF], macrophage colony-stimulating factor [M-CSF], interleukin 3 [IL-3], erythropoietin [Epo], and thrombopoietin [Tpo]) [4]. However, evidence has accumulated that in addition to this potent factors there are several peptide-based and non-peptide-based modulators of hematopoietic development. Examples include pituitary somatotropins (follicle-stimulating hormone [FSH], luteinizing hormone [LH], prolactin [PRL], and growth hormone [GH]) and gonadal sex hormones (estrogens, androgens, and thyroid hormones) [5-9]. 
A major role in the migration of HSPCs has been assigned to the $\alpha$-chemokine stromal-derived factor 1 (SDF-1) $[10,11]$; however, evidence has accumulated that bioactive phosphosphingolipids (sphingosine-1-phosphate [S1P] and ceramide-1-phosphate [C1P]) [12-14] as well as nucleotides secreted into the extracellular space (e.g., adenosine triphosphate [ATP]) and nucleosides (e.g., adenosine) [15-17] may affect hematopoietic development and postnatal migration of HSPCs.

Finally, the appropriateness of the available in vitro and in vivo animal models for studying hematopoietic development is clouded by several issues. First, we still do not know what is the most primitive stem cell ("pre-HSC") endowed with hematopoietic potential that resides in postnatal tissues. Such cells should undergo asymmetric divisions, and conclusive evidence for the existence of the most primitive CD $34^{+} \mathrm{CD} 45^{+} \operatorname{lin}^{-} \mathrm{HSCs}$ currently proposed is still missing. Moreover, for obvious reasons, murine HSPCs are tested in vivo in long-term engrafting assays and serial transplants in mice, but human HSPCs are tested in vivo in immunodeficient mice, sheep fetuses, and other surrogate models (e.g., humanized mice) to better mimic the human hematopoietic microenvironment [4]. However, these assays are sometimes difficult to perform (e.g., serial transplants with human cells in immunodeficient mice), expensive (e.g., large animal models) and not always easy for interpretation. Useful information about hematopoietic development is gained in the zebrafish model, but since hematopoiesis in zebrafish occurs in the kidney instead of in bone marrow (BM), this otherwise elegant model has also some downsides [18].

Finally, it is clear that major hematopoietic organs are affected by signals derived from the neural system $[19,20]$, the gut microbiota $[21,22]$, the redox (reduction and oxidation) potential of the hematopoietic microenvironment [23, 24], and the biological effects from activation of the complement cascade (ComC), the coagulation cascade (Coa), and the fibrinolytic cascade (FibC) $[25,26]$. In addition, extracellular microvesicles (ExMVs) [27, 28], which are secreted by cells in BM microenvironment, have emerged as new players in cell-to-cell communication.

This review seeks to shed more light on these unconventional and novel regulators of hematopoietic development and to present a broader picture of developmental and post-natal hematopoiesis.

\section{The Classical Regulators of Hematopoiesis}

The most attention has been paid to classical hematopoietic growth factors and cytokines, which are employed in clonogenic assays in vitro to study colony formation by hematopoietic progenitor cells (HPCs) at different levels of their specification and maturation into hematopoietic lineages [4]. These progenitors are described as colony-forming units for mixed lineages (CFU-Mix), burst-forming units and colony-forming units for the erythroid lineage (BFU-E and BFU-E, respectively), burstforming units and colony-forming units for the megakaryocytic lineage (BFU-Meg and CFU-Meg, respectively) as well as colony-forming units for granulocytes-monocytes (CFU-GM), granulocytes (CFU-G), monocytes (CFU-M), eosinophils (CFU-Eos), and basophils (CFU-Baso). These colonies are stimulated by combinations of (KL, Epo, Tpo, IL-3, GM-CSF, GCSF, M-CSF. IL-4, and IL-5, Fig. 1a). More primitive HSPCs, such as those giving rise to cobblestone area-forming units or long-term repopulating hematopoietic stem cells (LT-HSCs), are potentially supported by BM-derived fibroblasts [4].

In this review we will not discuss these classical potent regulators, which are already treated in excellent publications [29-31], and instead focus mainly on other unconventional modulators of hematopoietic development.

\section{Other Peptide- and Non-peptide-Based Regulators of Hematopoiesis}

Several factors have been described that regulate or coregulate in a synergistic way the very early stages of embryonic hematopoiesis, including the specification of mesodermal precursors (pre-HSCs) and/or putative common endothelial-hematopoietic progenitor cells (hemangioblasts?) into HSCs $[32,33]$. The most important are bone morphogenetic protein 2 and 4 (BMP-2 and BMP-4), basic fibroblast growth factor (bFGF), hepatocyte growth factor (HGF), and vascular endothelial factor (VEGF) [4].

Below we will address some other non-conventional regulators of hematopoietic development.

Pituitary Hormones Evidence has accumulated that several pituitary hormones, including follicle-stimulating hormone (FSH), luteinizing hormone (LH), prolactin (PRL), and growth hormone $(\mathrm{GH})$, directly stimulate hematopoietic development by interacting with specific receptors expressed on the surface of HSCs [5, 6]. Functional receptors for these hormones have been described, not only on murine and human HSCs but also on more primitive populations of very small embryonic-like stem cells (VSELs), which are postulated to be the most primitive stem cells in postnatal BM and endowed with the potential to be specified into cells from different germ layers, including hematopoiesis [33, 36, 37]. In vivo injection of these hormones into mice expands the number of VSELs and HSCs in BM. Similalry, it has been reported that FSH may accelerate hematopoietic recovery in 5-FU-treated mice [38]. Moreover, the hematopoiesis-promoting effects of PRL [35] and LH [34] have been recently demonstrated also by other investigators.

Gonadal Sex Hormones The beneficial effects of steroidbackbone sex hormones on hematopoiesis is well documented for androgens, which have been employed for several years in 




Fig. 1 Current topics in the development of hematopoietic stem cells. a An open question is the phenotype of the most primitive hematopoietic stem cells (pre-HSCs) that give rise to HSCs and HPCs and perhaps other stem cells in BM microenvironment (EPCs, MSCs). It has been hypothesized that VSELs possess hemangioblast activity and are able to differentiate to both HSCs and EPCs. The most important peptide based factors operating at different levels of HSPCs specification into the various hematopoietic lineages are indicated. b The chemoattractants for HSPCs that have been identified so far are shown. In addition to SDF-1, some non-peptide-based factors, including ATP, S1P, and C1P,

the clinic as stimulators of hematopoiesis in cases of BM aplasia [8]. It has also been proposed that estrogens compensate for the loss of blood during menstruation in females. Overall, estrogens promote the cell cycle activity of HSPCs and induce their specification into megakaryocyte-erythroid progenitors, as seen for example during pregnancy [7]. Hematopoiesis in vivo is also stimulated in mice after the injection of progesterone. Interestingly, expression of pituitary and gonadal sex hormone receptors has been detected in murine and human VSELs and HSCs, which suggests a common developmental origin of these cells from migrating primordial germ cells (PGCs) $[36,37]$. The potential developmental link between PGCs, VSELs, and HSCs is discussed later in this review.

Other Hormones In addition to gonadal sex hormones, other steroid-backbone hormones, such as glucocorticoids, are known for their positive effect on erythropoiesis and megakaryopoiesis [39]. They also indirectly affect leukocytosis by increasing the number of circulating neutrophils due to an accelerated release from BM and a reduced migration from the circulation. At the same time glucocorticoids reduce the play an important role in both mobilization and homing of HSPCs. c Bone marrow is a tissue highly responsive to cues derived from damaged organs, including from stress, strenuous exercise, irradiation, pro-mobilizing agents, and gut microbiota. All these cues activate a state of "sterile inflammation" in BM microenvironment. d The current problems with expansion of HSCs are related to the problem that asymmetric division is needed to maintain the most primitive HSCs in an expanded pool of cells. VSELs seem to be an ideal starting population for this purpose, and it is worthwhile to explore them further and optimize their ex vivo expansion for this purpose

number of circulating lymphocytes, monocytes, eosinophils, and basophils. The last stages of erythroid specification at the level of CFU-E progenitors are co-regulated by insulin-like growth factor 1 (IGF-1, also known as somatomedin C), which is secreted mainly from the liver into the circulation in response to GH stimulation [39, 40].

In zebrafish, an important role in the early stages of hematopoiesis has been documented for the extracellular nucleoside $(\mathrm{EXN})$ adenosine [41]. The role of the entire family of EXNs in regulating trafficking of HSPCs and hematopoietic development will be discussed later in this review.

\section{The Developmental Origin of HSCs, and Is there a Link to Primordial Germ Cells (PGCs)?}

The responsiveness of HSPCs to germ line-associated pituitary and gonadal sex hormones raises an important question: How are these cells responsive to these regulators? This important question can be answered by the fact that the first stem cells that become specified in the earliest stages of embryogenesis in the 
epiblast of the post-implantation blastocyst are primordial germ cells (PGCs) [36, 37, 42]. The epiblast is a precursor of the entire embryo proper, and PGCs are precursors of gametes, which pass genetic information, encoded in parental DNA and mitochondria, to the next generation. These cells, endowed with developmental totipotency, become specified in the proximal part of the epiblast and, shortly after specification, leave the embryo proper and migrate for a short period of time to the extra-embryonic mesoderm at the bottom of the yolk sac, where they begin to amplify, make a turn, and again enter the embryo proper through the primitive streak [42]. While continuing to be amplified in number, the PGCs migrate toward the genital ridges, where they settle and initiate gametogenesis. On their migratory route through the embryo proper toward the genital ridges they cross the part of the embryo called the aorta-gonado-mesonephros (AGM) region. In the wall of the dorsal aorta within this region the first definitive HSCs can be identified [31, 42].

Interestingly, the developmental route of PGCs during embryogenesis overlaps with the emergence of the first primitive HSCs in time and space-first in the so-called blood islands at the bottom of the yolk sac and later with the emergence of definitive HSCs in the AGM region of the developing embryo proper [31, 42]. Furthermore, both PGCs and HSCs are highly migratory stem cells, and it is very likely that some of the PGCs, while migrating in the extra-embryonic mesoderm, give rise as proposed to VSELs [36, 42] and VSEL-derived hemangioblasts $[36,37,43,44]$, which are precursors for both primitive HSCs and endothelial progenitor cells (EPCs). We envision that, while they migrate in the embryo proper through the AGM region towards the genital ridges, some of these cells become specified into definitive HSCs, which are detectable in the hemangiogenic endothelium of the dorsal aorta [37]. Other independent group that since many years studies migration of PGCs has also proposed this possibility recently [42]. Nevertheless, direct evidence is needed to demonstrate that VSEL can give rise to both HSC and EPC and thus comply with definition of hemangioblast. Such experiments are currently performed in our laboratory.

The developmental link between PGCs, VSELs, and HSCs may explain why VSELs and HSCs are responsive to several pituitary gonadotrophins and gonadal sex hormones and share certain molecular markers typical of germ development, such as the Sall4 germ line-specific transcription factor [37]. On the other hand, some germ line-derived cells (e.g., teratocarcinoma or gonadal cancer cells) express the erythropoietin receptor, which is known to be expressed by hemangioblasts and cells from the erythroid lineage [45].

\section{Modulators of Developmental and Post-Development Trafficking of HSPCs}

HSCs are restless travelers [46-53]. After being specified as discussed above in the blood islands at the bottom of the yolk sac and later emerging in the hematogenic endothelium of the dorsal aorta in the AGM region, they migrate to the fetal liver, which becomes a major hematopoietic organ in the second trimester of gestation, both in mice and in humans. Subsequently, at the beginning of the third trimester of gestation they migrate from the fetal liver to the hematopoietic microenvironment of BM. Later in adult life, a small number of HSPCs circulates in peripheral blood and follows a circadian rhythm, in which the peak in their numbers occurs in the early morning hours and the nadir late at night [19.20,25,53].

HSPCs, in contrast to more mature hematopoietic and lymphopoietic cells (e.g., granulocytes, monocytes, or lymphocytes), respond by chemotaxis to a limited number of factors [47]. So far, besides the $\alpha$-chemokine stromal-derived factor (SDF-1), which from a historical point of view is a "classical" chemoattractant for HSPCs, two bioactive phosphosphingolipids (S1P and C1P) [12-14] and the extracellular nucleotide ATP [15-17] have been described. These factors play a role not only in trafficking of adult HSPCs, as seen during mobilization and homing/engraftment, but most likely also during the developmental migration of HSPCs.

Stromal-Derived Factor 1 (SDF-1) SDF-1 is a well-known chemoattractant for fetal liver-residing HSPCs, which express its specific receptor, CXCR4, and by the end of the second trimester of gestation the SDF-1-CXCR4 axis relocates these cells to the hematopoietic microenvironment in developing bones [10, 11]. However, it is still not known which chemoattractant is crucial for attracting HSPCs from the anatomical sites where hematopoiesis is initiated (blood islands in the yolk sac and the dorsal aorta) into the fetal liver, as SDF-1-KO and CXCR-KO mice die in utero and have a normal number of myeloid HSPCs in their fetal liver $[10,11]$. It is possible that S1P, C1P, or ATP here play an important role $[47,54]$. Moreover, when studying SDF-1 as a chemoattractant one has to consider that, in experimental chemotaxis assays in vitro, this chemokine is employed at supraphysiological concentrations [47]. Therefore, more attention should be focused on S1P, C1P and ATP chemotactic activities, which are very potent chemoattractants for these cells at tissueexpressed (physiological) levels (Fig. 1b). These non-peptidebased factors are discussed below.

Bioactive Phosphosphingolipids (S1P and C1P) Initially, S1P was identified as an important regulator of the trafficking of lymphoid cells [55]. However, in the meantime evidence has accumulated that HSPCs strongly respond to chemotactic gradients of S1P and C1P. An increase in these gradients in peripheral blood (PB) during the mobilization of HSPCs directs their egress from BM [12-14, 56]. Similarly, an increase in $\mathrm{S} 1 \mathrm{P}$ and $\mathrm{C} 1 \mathrm{P}$ level in BM after conditioning for transplantation plays a supportive role in SDF-1-mediated homing and engraftment of these cells. Functional receptors for S1P $\left(\mathrm{S}_{\mathrm{P}} \mathrm{P}_{\mathrm{R} 1-5}\right)$ are expressed on HSCs, and $\mathrm{S}_{1} \mathrm{P}_{\mathrm{R} 1}$ and $\mathrm{S}_{1} \mathrm{P}_{\mathrm{R} 3}$ seem 
to be most important in regulating the trafficking of HSPCs [57]. In contrast to S1P receptors, the receptor/s for C1P have not yet been identified. However, the inhibition of C1Pmediated chemotaxis by pertussis toxin suggest that, like S1P, these receptors are $G_{i}$ protein-coupled, seventransmembrane-spanning receptors [47].

Extracellular Nucleotides Adenosine triphosphate (ATP) is known to be involved in energy transfer inside cells. However, ATP is also released from activated and stressed cells and in the extracellular compartment becomes an important signaling molecule involved in purinergic signaling [15, $58,59]$. In the extracellular space ATP is hydrolyzed to ADP, AMP, and finally adenosine, which are all mediators of purinergic signaling. The purinergic signaling receptor family is comprised of seven P2X (P2X1-7), eight P2Y (P2Y1, 2, 4, $6,11,12,13$, and 14), and four P1 (A1, A2a, A2b, and A3) receptors expressed on the surface of hematopoietic cells, including HSPCs. The P1 and P2Y receptors are G proteincoupled receptors, while the $\mathrm{P} 2 \mathrm{X}$ receptors are ligand-gated ion channel receptors [59]. While ATP stimulates P2X receptors, adenosine stimulates $\mathrm{P} 1$ receptors. In addition to ATP, P2Y receptors are stimulated by other nucleotides, including ADP, UTP, UDP, and UDP-glucose [58, 59]. ATP is an important modulator of HSPC trafficking; however, exposure to high levels of ATP may lead to apoptosis of these cells. The involvement of adenosine in the early stages of hematopoiesis in zebrafish was mentioned above [41]. Our results indicate that, while ATP promotes migration of HSPCs, adenosine is an important inhibitor of migration $[16,17]$.

Adrenergic Signaling It has also been demonstrated that mobilization of HSPCs is regulated by $\beta$-adrenergic signaling [19, $20]$. Bone marrow tissue is innervated and sympathetic synapses identified in proximity to BM stromal cells. Adrenergic signaling has been implicated in regulating the circadian release of HSPCs from BM into PB. Nevertheless, one must consider that this effect could be co-regulated by purinergic signaling, as ATP is released together with adrenalin into the synaptic space, and purinergic receptors are highly expressed on neural cells as well as in synapses [58]. However, this intriguing concept requires further experimental support.

\section{Sterile Inflammation of the Bone Marrow Microenvironment}

Bone marrow tissue is a dynamic structure that is highly responsive to several non-inflammatory cues related to stress, tissue or organ injuries, strenuous exercise, gut microbiota-derived signals, certain drugs, and radio-therapy (Fig. 1c) [17, 47]. Moreover, this dynamic environment of BM tissue coordinates signals derived from activation of the complement cascade
(ComC), the coagulation cascade (Coa), the fibrinolytic cascade (FibC), mediators of the neural system, and the redox state of the organism $[50,51]$. In all these situations danger-associated molecular pattern molecules (DAMPs) are released from the affected cells and activate i) cell-surface Toll-like receptors and ii) intracellular nucleotide-binding oligomerization domain (NOD)-like receptors (e.g., Nlrp) [49]. As demonstrated recently, the intracellular Nlrp3 receptor, known as the Nlrp3 inflammasome, is crucial for regulating the trafficking of normal HSPCs under both steady-state and stress conditions, including pharmacological mobilization $[60,61]$. The Nlrp3 inflammasome is activated by the ATP-P2X7 receptor interaction, which leads to the release of DAMPs (high molecular group box 1 [HMGB1] and S1009a) and certain cytokines (IL-1 $\beta$ and IL-18) $[62,63]$, which activate the ComC and $\mathrm{CoaC}$. These mutual interactions provide a basis for better understanding how innate immunity regulates hematopoiesis.

In a state of infection, these receptors may also be activated by pathogen-associated molecular patter molecules (PAMPs). By contrast, under steady-state conditions physiological commensal bacteria, such as those in the gut, may also indirectly affect bone marrow by secreted liposaccharide (LPS). LPS activates toll-like receptor 4 (TLR4) and primes the Nlrp3 inflammasome for synthesis of IL-1 $\beta$ and IL-18 $[62,63]$. Depletion of the gut microbiota by antibiotics impairs hematopoiesis and the trafficking of HSPCs [21, 22]. Mice exposed to antibiotics that eliminate gut microbiota are poor mobilizers of HSPCs. This effect is most likely mediated by a decrease in the priming effect of LPS, via the TLR4 receptor, on the basic tonus of the Nlrp3 inflammasome and synthesis of IL-1 $\beta$ and IL-18 [62, 63].

In addition to these interactions, a new player in cell-to-cell communication has emerged: extracellular microvesicles (ExMVs) [27, 28]. ExMVs secreted from mesenchymal cells have been demonstrated to protect HSPCs from irradiation injury in the BM microenvironment. The biological effects of ExMVs are mediated by their cargo, which includes mRNA, miRNA, proteins, and bioactive lipids that inhibit apoptosis and promote proliferation of HSPCs [64]. ExMVs have been demonstrated to facilitate engraftment of HSPCs as well as directly stimulate HSC proliferation. In allogeneic hematopoietic transplantation they may also ameliorate graft-versus-host disease (GvHD) [65]. The role of ExMVs in hematopoiesis is an exciting and still largely unwritten chapter in stem cell biology.

\section{Strategies to Accelerate Hematopoietic Reconstitution after Transplantation of HSPCs}

Successful and rapid engraftment of HSPCs after transplantation directly impacts the survival rate of patients. It can be achieved by transplantation of a high number of HSPCs directly obtained from a donor or their effective ex vivo expansion before administration to the patient [47]. Therefore, on the one hand, 
optimization of stem cell mobilization protocols is crucial for harvesting a high number of HSPCs for transplantation. Besides G-CSF or AMD3100, other potent co-stimulators of mobilization have been proposed for testing in the clinic including $\mathrm{N}$ terminal truncated form of the human CXC chemokine GRObeta [66], inhibitor of adhesion molecule very late antigen-4 (VLA-4) inhibitor [67] and dipeptidylpeptidase-4/CD26 (DPP4/CD26) truncation product the neurotransmitter neuropeptide Y (NPY) [68]. The armamentarium of such potential pro-mobilizing agents has increased, and recent research has also demonstrated that mobilization is enhanced by the addition of i) drugs that increase the level of S1P in PB [69], ii) inhibitors of extracellular adenosine synthesis in the bone marrow microenvironment $[16,17]$, or iii) inhibitors of heme oxygenase 1 (HO-1) [70, 71] and inducible nitric oxide synthetize [72], intracellular enzymes which inhibit the mobilization process.

On the other hand, in the case of poor mobilizers or poor donors of BM cells, an important option is ex vivo expansion of harvested HSPCs. Here, however, is a problem, as most of the expansion protocols using cocktails of growth factors expand mostly HPCs at the expense of HSCs [47]. Nevertheless, a significant breakthrough in expansion strategies has been achieved by using, in addition to cocktails of growth factors or cytokines, small molecules such as StemRegenin (SR1), an aryl hydrocarbon receptor (AhR) antagonist [73]; nicotinamide (NAM), an amide form of vitamin B3 [74]; or a pyrimidoindole derivative (UM171) [75]. What is intriguing, both UM171 and NMA were also successfully employed to expand ex vivo VSELs into HSCs [76, 77].

Interestingly, in all reported expansion approaches using NMA and UM171 small-molecule modifiers, the HSCs for expansion were isolated using paramagnetic beads against CD34 or CD133 antigens expressed by these cells [74, 75, 78]. Therefore, from a suspension of BM, $\mathrm{mPB}$, or UCB hematopoietic cells, paramagnetic beads pull down both large and small CD34 and/or CD133 cells. Since small VSELs express both CD34 and CD133 antigen, they are co-isolated with larger HSCs. Taking into consideration the kinetics of expansion, we hypothesize that cells expanded using these protocols were in fact pre-HSCs or VSELs [47, 76, 77]. This question needs further clarification, and the potential positioning of VSELs in the hierarchy of stem cells during ex vivo expansion is depicted in Fig. 1d. With this hierarchy in mind, VSELs seem to be the most suitable cells for expansion and asymmetric division and would likely maintain the pool of the most primitive pre-HSCs during this procedure.

\section{Future Directions in HSPC Research and Applications}

Despite significant progress in understanding hematopoiesis, there are several issues that still have to be addressed. First, as mentioned above, it is still not clear what are the most primitive stem cells in BM that give rise to HSCs. Evidence accumulated that this are VSELs [43, 47, 79, 80]. Interestingly, since we expect from most primitive stem cells to undergo assymetric divisions, recently published data demonstrated that VSELs indeed undergo assymetric divisions. Accordingly, $\mathrm{CD}_{4} 5^{-} \mathrm{NUMB}^{-}$VSELs differentiate into $\mathrm{CD} 45^{+} \mathrm{NUMB}^{+} \mathrm{HSCs}[80]$. The NUMB protein is evolutionary conserved and plays a role in the determination of cell fates during development. NUMB localizes to one side of the mother cell and it is distributed selectively to one daughter cell only during assymetric division. This division allows a daughter cell that contains NUMB protein to acquire a different fate than the other daughter cell after division [81].

Moreover, it is still an open question whether adult tissues contain a hemangioblast, a stem cell that can give a rise to HSCs and endothelial progenitor cells (EPCs) [32, 33]. This possibility has several pros and cons, and more research is needed to give a final answer. In this context it is very likely that the VSELs reported in adult postnatal tissues can be enriched for a population of putative hemangioblasts [33]. Next, since the number of HSPC donors is limited, it is important to identify new sources of these cells for clinical applications. It has been proposed that HSPCs could be generated from embryonic stem cells (ESCs) or induced pluripotent stem cells (iPSCs) [82]. However, the problem with these cells is that, aside from the risk of teratoma formation and rejection by the recipient, they have significant genomic instability, and so far no engraftable HSPCs have been derived from ESCs or iPSCs [82, 83]. Here again, adult tissue-derived VSELs, which have been successfully expanded into the hematopoietic lineage and can be engrafted in immunodeficient mice $[82,84]$, could become a valuable option for solving this problem. In addition to SR1, NAM, and UM171, other potent expansion-promoting molecules have been developed. Again these new compounds (e.g., BIO or GSK3 $\beta$ inhibitor, trichostatin A, NR1010) should be tested for expansion and hematopoietic specification of VSELs.

Since HSPCs from mPB are a valuable source of cells for transplantation, more efficient mobilization strategies for cases of poor mobilizers should be developed. Moreover, it is important to identify genetic markers for poor mobilizers. As previously demonstrated, one of the crucial pathways involved in mobilization is activation of purinergic signaling. In this pathway, ATP is released from stressed cells by pannexin 1 channels and binds to $\mathrm{P} 2 \mathrm{X} 7$ purinergic receptors to activate the Nlrp3 inflammasome [59-61]. Our recent patient results revealed that $\sim 60 \%$ of patients that were poor HSPC mobilizers $(n=20)$ displayed the pannexin 1 polymorphism SNP5 (Rs3020015) T/C. By contrast, this polymorphism was observed in only 1 out of 26 good-mobilizer patients $(\sim 4 \%)$ (manuscript in preparation). Furthermore, as recently reported, the presence of the Gln460Arg SNP polymorphism within 
the purinergic $\mathrm{P} 2 \mathrm{X} 7$ receptor gene in HSPCs, which is always co-inherited with Ala348Thr to form the gain-of-function haplotype 4, resulted in a significant increase in $\mathrm{CD} 34^{+}$HSPC mobilization [85]. This again supports the important role of purinergic signaling in this process [15-17].

Finally, an important task is to improve the seeding efficiency of transplanted HSPCs to BM hematopoietic niches. To facilitate this process, ex vivo priming strategies have been proposed in which the cells to be grafted are selected according to their responsiveness to a homing gradient of SDF-1 [47]. This process could be enhanced by processing HSPCs for transplant in hypoxic conditions [23, 24] or exposing them to short term mild heating in $39^{\circ} \mathrm{C}$ [86], overexpressing in these cells HOXB4 [87] or pharmacological upregulation of HIF-1a by caffeic acid phenentyl ester [88]. Moreover, some factors have been identified, including anti-microbial cationic peptides that are part of the innate immunity response, such as (i) the complement cascade cleavage fragment $\mathrm{C} 3 \mathrm{a}$, (ii) cathelicidin (LL-37), and iii) $\beta 2$-defensin, which are induced by activation of the ComC in BM stroma during conditioning for transplantation of HSPCs [89]. A short exposure of HSPCs to these factors conditions them for transplantation before injection into recipients and accelerates homing and engraftment [90]. This is explained by increased incorporation of CXCR4 homing receptor for SDF-1 into membrane lipid rafts [91]. Interestingly, a similar effect is achieved by exposure of HSPCs to prostaglandin E2 (PGE2) as explained due to upregulation of CXCR4 receptor on HSCs [91]. Other potential strategies facilitating homing of HSPCs were the subject of a recent review in Stem Cell Reviews and Reports [92].

Moreover, since intracellular HO-1 in HSPCs negatively affects their migration, homing and engraftment, exposure of cells in the graft to small-molecule inhibitors of HO-1 could enhance hematopoietic reconstitution. This has been demonstrated in an in vivo model in mice [93].

Many of these promising strategies mentioned above were obtained in experimental animal models and await validation in well controlled clinical studies.

\section{Conclusions}

Hematopoiesis and development of HSPCs are intriguing and still hold many secrets. Bold new concepts, validated by experiments, are needed to unleash their full regenerative potential. Paradigms in science change with time and, as Albert Einstein stated, "Blind belief in authority is the greatest enemy of truth" and as his countryman Max Planck said "One rule is important in science-only courageous people win". In hematopoiesis there are still many doors to be opened in order to understand this fascinating cell system, and courageous young investigators are needed. In pursuing scientific truth it is also important to be critical and to keep in mind another famous saying from Albert Einstein "Anyone who has never made a mistake has never tried anything new" and one from Maria Sklodowska-Curie "I was thought that the way of progress is neither swift or easy".

Acknowledgements This work was supported by NIH grants $2 \mathrm{R} 01$ DK074720, the Stella and Henry Endowment, and the OPUS grant DEC-2016/23/B/NZ3/03157 to MZR.

Open Access This article is distributed under the terms of the Creative Commons Attribution 4.0 International License (http:// creativecommons.org/licenses/by/4.0/), which permits unrestricted use, distribution, and reproduction in any medium, provided you give appropriate credit to the original author(s) and the source, provide a link to the Creative Commons license, and indicate if changes were made.

\section{References}

1. Thomas, E. D., \& Epstein, R. B. (1965). Bone marrow transplantation in acute leukemia. Cancer Research, 25(9), 1521-1524.

2. Körbling, M. (1991). The role of stem cell mobilization in the scope of autologous blood stem cell transplantation. Beitrage zur Infusionstherapie, 28, 233-241.

3. Gluckman, E., Broxmeyer, H. A., Auerbach, A. D., Friedman, H. S., Douglas, G. W., Devergie, A., Esperou, H., Thierry, D., Socie, G., \& Lehn, P. (1989). Hematopoietic reconstitution in a patient with Fanconi's anemia by means of umbilical-cord blood from an HLA-identical sibling. The New England Journal of Medicine, 321(17), 1174-1178.

4. Ratajczak, M. Z. (2008). Phenotypic and functional characterization of hematopoietic stem cells. Current Opinion in Hematology, 15(4), 293-300.

5. Mierzejewska, K., Borkowska, S., Suszynska, E., Suszynska, M., Poniewierska-Baran, A., Maj, M., Pedziwiatr, D., Adamiak, M., Abdel-Latif, A., Kakar, S. S., Ratajczak, J., Kucia, M., \& Ratajczak, M. Z. (2015). Hematopoietic stem/progenitor cells express several functional sex hormone receptors-novel evidence for a potential developmental link between hematopoiesis and primordial germ cells. Stem Cells and Development, 24(8), 927-937.

6. Abdelbaset-Ismail, A., Suszynska, M., Borkowska, S., Adamiak, M., Ratajczak, J., Kucia, M., \& Ratajczak, M. Z. (2016). Human haematopoietic stem/progenitor cells express several functional sex hormone receptors. Journal of Cellular and Molecular Medicine, 20(1), 134-146.

7. Sánchez-Aguilera, A., Arranz, L., Martín-Pérez, D., García-García, A., Stavropoulou, V., Kubovcakova, L., Isern, J., MartínSalamanca, S., Langa, X., Skoda, R. C., Schwaller, J., \& MéndezFerrer, S. (2014). Estrogen signaling selectively induces apoptosis of hematopoietic progenitors and myeloid neoplasms without harming steady-state hematopoiesis. Cell Stem Cell, 15(6), 791804.

8. Shahani, S., Braga-Basaria, M., Maggio, M., \& Basaria, S. (2009). Androgens and erythropoiesis: Past and present. The Journal of Endocrinological Investigation, 32(8), 704-716.

9. Bauer, A., Mikulits, W., Lagger, G., Stengl, G., Brosch, G., \& Beug, H. (1998). The thyroid hormone receptor functions as a ligandoperated developmental switch between proliferation and differentiation of erythroid progenitors. The EMBO Journal, 17(15), 42914303.

10. Nagasawa, T., Hirota, S., Tachibana, K., Takakura, N., Nishikawa, S., Kitamura, Y., Yoshida, N., Kikutani, H., \& Kishimoto, T. (1996). Defects of B-cell lymphopoiesis and bone-marrow 
myelopoiesis in mice lacking the CXC chemokine PBSF/SDF-1. Nature, 382, 635-638.

11. Zou, Y. R., Kottmann, A. H., Kuroda, M., Taniuchi, I., \& Littman, D. R. (1998). Function of the chemokine receptor CXCR4 in haematopoiesis and in cerebellar development. Nature, 393, 595599.

12. Ratajczak, M. Z., Lee, H., Wysoczynski, M., Wan, W., Marlicz, W., Laughlin, M. J., Kucia, M., Janowska-Wieczorek, A., \& Ratajczak, J. (2010). Novel insight into stem cell mobilization-plasma sphingosine-1-phosphate is a major chemoattractant that directs the egress of hematopoietic stem progenitor cells from the bone marrow and its level in peripheral blood increases during mobilization due to activation of complement cascade/membrane attack complex. Leukemia, 24(5), 976-985.

13. Golan, K., Vagima, Y., Ludin, A., Itkin, T., Cohen-Gur, S., Kalinkovich, A., Kollet, O., Kim, C., Schajnovitz, A., Ovadya, Y., Lapid, K., Shivtiel, S., Morris, A. J., Ratajczak, M. Z., \& Lapidot, T. (2012). S1P promotes murine progenitor cell egress and mobilization via S1P1-mediated ROS signaling and SDF-1 release. Blood, 119(11), 2478-2488.

14. Juarez, J. G., Harun, N., Thien, M., Welschinger, R., Baraz, R., Pena, A. D., Pitson, S. M., Rettig, M., DiPersio, J. F., Bradstock, K. F., \& Bendall, L. J. (2012). Sphingosine-1-phosphate facilitates trafficking of hematopoietic stem cells and their mobilization by CXCR4 antagonists in mice. Blood, 119(3), 707-716.

15. Rossi, L., Salvestrini, V., Ferrari, D., Di Virgilio, F., \& Lemoli, R. M. (2012). The sixth sense: Hematopoietic stem cells detect danger through purinergic signaling. Blood, 120(12), 2365-2375.

16. Adamiak, M., Bujko, K., Cymer, M., Plonka, M., Glaser, T., Kucia, M., Ratajczak, J., Ulrich, H., Abdel-Latif, A., \& Ratajczak, M. Z. (2018). Novel evidence that extracellular nucleotides and purinergic signaling induce innate immunity-mediated mobilization of hematopoietic stem/progenitor cells. Leukemia, 32(9), 1920-1931.

17. Ratajczak, M. Z., Adamiak, M., Plonka, M., Abdel-Latif, A., \& Ratajczak, J. (2018). Mobilization of hematopoietic stem cells as a result of innate immunity-mediated sterile inflammation in the bone marrow microenvironment-the involvement of extracellular nucleotides and purinergic signaling. Leukemia, 32(5), 1116-1123.

18. Boatman, S., Barrett, F., Satishchandran, S., Jing, L., Shestopalov, I., \& Zon, L. I. (2013). Assaying hematopoiesis using zebrafish. Blood Cells, Molecules \& Diseases, 51(4), 271-276.

19. Méndez-Ferrer, S., Chow, A., Merad, M., \& Frenette, P. S. (2009). Circadian rhythms influence hematopoietic stem cells. Current Opinion in Hematology, 16, 235-242.

20. Hanoun, M., Maryanovich, M., Arnal-Estapé, A., \& Frenette, P. S. (2015). Neural regulation of hematopoiesis, inflammation and cancer. Neuron, 86, 360-373.

21. Velders, G. A., van Os, R., Hagoort, H., Verzaal, P., Guiot, H. F., Lindley, I. J., Willemze, R., Opdenakker, G., \& Fibbe, W. E. (2004). Reduced stem cell mobilization in mice receiving antibiotic modulation of the intestinal flora: Involvement of endotoxins as cofactors in mobilization. Blood, 103(1), 340-346.

22. Josefsdottir, K. S., Baldridge, M. T., Kadmon, C. S., \& King, K. Y. (2017). Antibiotics impair murine hematopoiesis by depleting the intestinal microbiota. Blood, 129(6), 729-739.

23. Mantel, C. R., O'Leary, H. A., Chitteti, B. R., Huang, X., Cooper, S., Hangoc, G., Brustovetsky, N., Srour, E. F., Lee, M. R., MessinaGraham, S., Haas, D. M., Falah, N., Kapur, R., Pelus, L. M., Bardeesy, N., Fitamant, J., Ivan, M., Kim, K. S., \& Broxmeyer, H. E. (2015). Antibiotics impair murine hematopoiesis by depleting the intestinal microbiota. Blood, 129(6), 729-739.

24. Huang, X., Trinh, T., Aljoufi, A., \& Broxmeyer, H. E. (2018). Hypoxia signaling pathway in stem cell regulation: Good and evil. Current Stem Cell Reports, 4(2), 149-157.

25. Budkowska, M., Ostrycharz, E., Wojtowicz, A., Marcinowska, Z., Woźniak, J., Ratajczak, M. Z., \& Dołęgowska, B. (2018). A circadian rhythm in both complement Cascade (ComC) activation and Sphingosine-1-phosphate (S1P) levels in human peripheral blood supports a role for the ComC-S1P Axis in circadian changes in the number of stem cells circulating in peripheral blood. Stem Cell Reviews and Reports, 14(5), 677-685.

26. Bujko, K., Rzeszotek, S., Hoehlig, K., Yan, J., Vater, A., \& Ratajczak, M. Z. (2017). Signaling of the complement cleavage product anaphylatoxin C5a through C5aR (CD88) contributes to pharmacological hematopoietic stem cell mobilization. Stem Cell Reviews and Reports, 13(6), 793-800.

27. Quesenberry, P., \& Goldberg, L. R. (2018). A new stem cell biology: Transplantation and baseline, cell cycle and exosomes. Advances in Experimental Medicine and Biology, 1056, 3-9.

28. Bruno, S., Chiabotto, G., Favaro, E., Deregibus, M. C., \& Camussi, G. (2017). Role of extracellular vesicles in stem cell biology. The American Journal of Physiology-Cell Physiology, 317(2), C303C313.

29. Scala, S., Leonardelli, L., \& Biasco, L. (2016). Current approaches and future perspectives for in vivo clonal tracking of hematopoietic cells. Current Gene Therapy, 16(3), 184-193.

30. Rieger, M. A., \& Schroeder, T. (2012). Hematopoiesis. Cold Spring Harbor Perspectives in Biology, 4(12).

31. Crisan, M., \& Dzierzak, E. (2016). The many faces of hematopoietic stem cell heterogeneity. Development, 143(24), 4571-4581.

32. Lacaud, G., \& Kouskoff, V. (2017). Hemangioblast, hemogenic endothelium, and primitive versus definitive hematopoiesis. Experimental Hematology, 49, 19-24.

33. Smadja, D. M. (2017). Bone marrow very small embryonic-like stem cells: New generation of autologous cell therapy soon ready for prime time? Stem Cell Reviews and Reports, 13(2), 198-201.

34. Zhang, W. C., Sun, R., Zhang, J., Zhang, J., \& Tian, Z. (2005). Recombinant human prolactin protects against irradiation-induced myelosuppression. Cellular \& Molecular Immunology, 2(5), 379385 .

35. Velardi, E., Tsai, J. J., Radtke, S., Cooper, K., Argyropoulos, K. V., Jae-Hung, S., Young, L. F., Lazrak, A., Smith, O. M., Lieberman, S., Kreines, F., Shono, Y., Wertheimer, T., Jenq, R. R., Hanash, A. M., Narayan, P., Lei, Z., Moore, M. A., Kiem, H. P., van den Brink, M. R. M., \& Dudakov, J. A. (2018). Suppression of luteinizing hormone enhances HSC recovery after hematopoietic injury. Nature Medicine, 24(2), 239-246.

36. Virant-Klun, I. (2016). Very small embryonic-like stem cells: A potential developmental Link between germinal lineage and hematopoiesis in humans. Stem Cells and Development, 25(2), 101-113.

37. Ratajczak, M. Z. (2017). Why are hematopoietic stem cells so 'sexy'? On a search for developmental explanation. Leukemia, 31(8), 1671-1677.

38. Shaikh, A., Bhartiya, D., Kapoor, S., \& Nimkar, H. (2016). Delineating the effects of 5-fluorouracil and follicle-stimulating hormone on mouse bone marrow stem/progenitor cells. Stem Cell Res Ther, 7(1), 19-59.

39. Lodish, H., Flygare, J., \& Chou, S. (2010). From stem cell to erythroblast: Regulation of red cell production at multiple levels by multiple hormones. IUBMB Life, 62(7), 492-496.

40. Ratajczak, J., Zhang, Q., Pertusini, E., Wojczyk, B. S., Wasik, M. A., \& Ratajczak, M. Z. (1998). The role of insulin (INS) and insulin-like growth factor-I (IGF-I) in regulating human erythropoiesis. Studies in vitro under serum-free conditions-comparison to other cytokines and growth factors. Leukemia, 12(3), 371-381.

41. Jing, L., Tamplin, O. J., Chen, M. J., Deng, Q., Patterson, S., Kim, P. G., Durand, E. M., McNeil, A., Green, J. M., Matsuura, S., Ablain, J., Brandt, M. K., Schlaeger, T. M., Huttenlocher, A., Daley, G. Q., Ravid, K., \& Zon, L. I. (2015). Adenosine signaling promotes hematopoietic stem and progenitor cell emergence. Journal of Experimental Medicine, 212(5), 649-663. 
42. Scaldaferri, M. L., Klinger, F. G., Farini, D., Di Carlo, A., Carsetti, R., Giorda, E., \& De Felici, M. (2015). Hematopoietic activity in putative mouse primordial germ cell populations. Mechanisms of Development, 136, 53-63.

43. Shaikh, A., Nagvenkar, P., Pethe, P., Hinduja, I., \& Bhartiya, D. (2015). Molecular and phenotypic characterization of CD133 and SSEA4 enriched very small embryonic-like stem cells in human cord blood. Leukemia, 29(9), 1909-1917.

44. Bhartiya, D., Patel, H., Ganguly, R., Shaikh, A., Shukla, Y., Sharma, D., \& Singh, P. (2018). Novel insights into adult and Cancer stem cell biology. Stem Cells and Development, 27(22), $1527-1539$.

45. Ratajczak, M. Z., Bujko, K., Mack, A., Kucia, M., \& Ratajczak, J. (2018). Cancer from the perspective of stem cells and misappropriated tissue regeneration mechanisms. Leukemia, 32(12), 2519-2526.

46. Pelus, L. M., \& Broxmeyer, H. E. (2018). Peripheral blood stem cell mobilization: A look ahead. Current Stem Cell Reports, 4, 273281.

47. Ratajczak, M. Z. (2015). A novel view of the adult bone marrow stem cell hierarchy and stem cell trafficking. Leukemia, 29(4), 776782.

48. Zhang, J., Supakorndej, T., Krambs, J. R., Rao, M., Abou-Ezzi, G., Ye, R. Y., Li, S., Trinkaus, K., \& Link, D. C. (2019). Bone marrow dendritic cells regulate hematopoietic stem/progenitor cell trafficking. Journal of Clinical Investigation, 129(7), 2920-2931.

49. Schuettpelz, L. G., \& Link, D. C. (2013). Regulation of hematopoietic stem cell activity by inflammation. Frontiers in Immunology, 4, 204.

50. Borkowska, S., Suszynska, M., Mierzejewska, K., Ismail, A., Budkowska, M., Salata, D., Dolegowska, B., Kucia, M., Ratajczak, J., \& Ratajczak, M. Z. (2014). Novel evidence that crosstalk between the complement, coagulation and fibrinolysis proteolytic cascades is involved in mobilization of hematopoietic stem/progenitor cells (HSPCs). Leukemia, 28(11), 2148-2154.

51. Nguyen, T. S., Lapidot, T., \& Ruf, W. (2018). Extravascular coagulation in hematopoietic stem and progenitor cell regulation. Blood, 132(2), 123-131.

52. Tay, J., Levesque, J. P., \& Winkler, I. G. (2017). Cellular players of hematopoietic stem cell mobilization in the bone marrow niche. International Journal of Hematology, 105(2), 129-140.

53. Lapid, K., Glait-Santar, C., Gur-Cohen, S., Canaani, J., Kollet, O., \& Lapidot, T. (2012). Egress and mobilization of hematopoietic stem and progenitor cells: A dynamic multi-facet process. Harvard Stem Cell Institute. https://doi.org/10.3824/stembook.1. 91.1.

54. Adamiak, M., Borkowska, S., Wysoczynski, M., Suszynska, M., Kucia, M., Rokosh, G., Abdel-Latif, A., Ratajczak, J., \& Ratajczak, M. Z. (2015). Evidence for the involvement of sphingosine-1phosphate in the homing and engraftment of hematopoietic stem cells to bone marrow. Oncotarget, 6(22), 18819-18828.

55. Obinata, H., \& Hla, T. (2019). Sphingosine 1-phosphate and inflammation. International Immunology, 31, 617-625. https://doi. org/10.1093/intimm/dxz037.

56. Kim, C. H., Wu, W., Wysoczynski, M., Abdel-Latif, A., Sunkara, M., Morris, A., Kucia, M., Ratajczak, J., \& Ratajczak, M. Z. (2012). Conditioning for hematopoietic transplantation activates the complement cascade and induces a proteolytic environment in bone marrow: A novel role for bioactive lipids and soluble $\mathrm{C} 5 \mathrm{~b}-\mathrm{C} 9$ as homing factors. Leukemia, 26(1), 106-116.

57. Ogle, M. E., Olingy, C. E., Awojoodu, A. O., Das, A., Ortiz, R. A., Cheung, H. Y., \& Botchwey, E. A. (2017). Sphingosine-1phosphate Receptor-3 supports hematopoietic stem and progenitor cell residence within the bone marrow niche. Stem Cells, 35(4), 1040-1052.
58. Oliveira, Á., Illes, P., \& Ulrich, H. (2016). Purinergic receptors in embryonic and adult neurogenesis. Neuropharmacology, 104, 272281.

59. Burnstock, G. (2015). Blood cells: An historical account of the roles of purinergic signalling. Purinergic Signalling, 11(4), 411-434.

60. Lenkiewicz, A. M., Adamiak, M., Thapa, A., Bujko, K., Pedziwiatr, D., Abdel-Latif, A. K., Kucia, M., Ratajczak, J., \& Ratajczak, M. Z. (2019). The Nlrp3 Inflammasome orchestrates mobilization of bone marrow-residing stem cells into peripheral blood. Stem Cell Reviews and Reports, 15(3), 391-403.

61. Adamiak, M., Lenkiewicz, A. M., Cymer, M., Kucia, M., Ratajczak, J., \& Ratajczak, M. Z. (2019). Novel evidence that an alternative complement cascade pathway is involved in optimal mobilization of hematopoietic stem/progenitor cells in Nlrp3 inflammasome-dependent manner. Leukemia. https://oi.org/10. 1038/s41375-019-0530-9.

62. Groslambert, M., \& Py, B. F. (2018). Spotlight on the NLRP3 inflammasome pathway. Journal of Inflammation Research, 11, 359-374.

63. Place, D. E., \& Kanneganti, T. D. (2018). Recent advances in inflammasome biology. Current Opinion in Immunology, 50, 3238.

64. Ratajczak, M. Z., \& Ratajczak, J. (2016). Horizontal transfer of RNA and proteins between cells by extracellular microvesicles: 14 years later. Clinical and Translational Medicine, 5(1), 7.

65. Fierabracci, A., Del Fattore, A., Luciano, R., Muraca, M., Teti, A., \& Muraca, M. (2015). Recent advances in mesenchymal stem cell immunomodulation: The role of microvesicles. Cell Transplantation, 24(2), 133-149.

66. King, A. G., Johanson, K., Frey, C. L., DeMarsh, P. L., White, J. R., McDevitt, P., McNulty, D., Balcarek, J., Jonak, Z. L., Bhatnagar, P. K., \& Pelus, L. M. (2000). Identification of unique truncated KC/ GRO beta chemokines with potent hematopoietic and anti-infective activities. Journal of Immunology, 164(7), 3774-3782.

67. Karpova, D., Rettig, M. P., Ritchey, J., Cancilla, D., Christ, S., Gehrs, L., Chendamarai, E., Evbuomwan, M. O., Holt, M., Zhang, J., Abou-Ezzi, G., Celik, H., Wiercinska, E., Yang, W., Gao, F., Eissenberg, L. G., Heier, R. F., Arnett, S. D., Meyers, M. J., Prinsen, M. J., Griggs, D. W., Trumpp, A., Ruminski, P. G., Morrow, D. M., Bonig, H. B., Link, D. C., \& DiPersio, J. F. (2019). Targeting VLA4 integrin and CXCR2 mobilizes serially repopulating hematopoietic stem cells. Journal of Clinical Investigation, 129(7), 2745-2759.

68. Singh, P., Hoggatt, J., Kamocka, M. M., Mohammad, K. S., Saunders, M. R., Li, H., Speth, J., Carlesso, N., Guise, T. A., \& Pelus, L. M. (2017). Neuropeptide Y regulates a vascular gateway for hematopoietic stem and progenitor cells. Journal of Clinical Investigation, 127(12), 4527-4540.

69. Adamiak, M., Chelvarajan, L., Lynch, K. R., Santos, W. L., AbdelLatif, A., \& Ratajczak, M. Z. (2017). Mobilization studies in mice deficient in sphingosine kinase 2 support a crucial role of the plasma level of sphingosine-1-phosphate in the egress of hematopoietic stem progenitor cells. Oncotarget, 8(39), 65588-65600.

70. Wysoczynski, M., Ratajczak, J., Pedziwiatr, D., Rokosh, G., Bolli, R., \& Ratajczak, M. Z. (2015). Identification of heme oxygenase 1 (HO-1) as a novel negative regulator of mobilization of hematopoietic stem/progenitor cells. Stem Cell Reviews and Reports, 11(1), $110-118$.

71. Abdelbaset-Ismail, A., Borkowska-Rzeszotek, S., Kubis, E., Bujko, K., Brzeźniakiewicz-Janus, K., Bolkun, L., Kloczko, J., Moniuszko, M., Basak, G. W., Wiktor-Jedrzejczak, W., \& Ratajczak, M. Z. (2017). Activation of the complement cascade enhances motility of leukemic cells by downregulating expression of HO-1. Leukemia, 31(2), 446-458.

72. Adamiak, M., Abdelbaset-Ismail, A., Moore, J. B., 4th, Zhao, J., Abdel-Latif, A., Wysoczynski, M., \& Ratajczak, M. Z. (2017). 
Inducible nitric oxide synthase (iNOS) is a novel negative regulator of hematopoietic stem/progenitor cell trafficking. Stem Cell Reviews and Reports, 13(1), 92-103.

73. Boitano, A. E., Wang, J., Romeo, R., Bouchez, L. C., Parker, A. E., Sutton, S. E., Walker, J. R., Flaveny, C. A., Perdew, G. H., Denison, M. S., Schultz, P. G., \& Cooke, M. P. (2010). Aryl hydrocarbon receptor antagonists promote the expansion of human hematopoietic stem cells. Science, 329(5997), 1345-1348.

74. Peled, T., Shoham, H., Aschengrau, D., Yackoubov, D., Frei, G., Rosenheimer, G. N., Lerrer, B., Cohen, H. Y., Nagler, A., Fibach, E., \& Peled, A. (2012). Nicotinamide, a SIRT1 inhibitor, inhibits differentiation and facilitates expansion of hematopoietic progenitor cells with enhanced bone marrow homing and engraftment. Experimental Hematology, 40(4), 342-355.

75. Fares, I., Chagraoui, J., Gareau, Y., Gingras, S., Ruel, R., Mayotte, N., Csaszar, E., Knapp, D. J., Miller, P., Ngom, M., Imren, S., Roy, D. C., Watts, K. L., Kiem, H. P., Herrington, R., Iscove, N. N., Humphries, R. K., Eaves, C. J., Cohen, S., Marinier, A., Zandstra, P. W., \& Sauvageau, G. (2014). Cord blood expansion. Pyrimidoindole derivatives are agonists of human hematopoietic stem cell self-renewal. Science, 345(6203), 1509-1512.

76. Lahlil, R., Scrofani, M., Barbet, R., Tancredi, C., Aries, A., \& Hénon, P. (2018). VSELs maintain their pluripotency and competence to differentiate after enhanced ex vivo expansion. Stem Cell Reviews and Reports, 14(4), 510-524.

77. Ratajczak, M. Z., Ratajczak, J., Suszynska, M., Miller, D. M., Kucia, M., \& Shin, D. M. (2017). A novel view of the adult stem cell compartment from the perspective of a quiescent population of very small embryonic-like stem cells. Circulation Research, 120(1), 166-178.

78. Horwitz, M. E., Chao, N. J., Rizzieri, D. A., Long, G. D., Sullivan, K. M., Gasparetto, C., Chute, J. P., Morris, A., McDonald, C., Waters-Pick, B., Stiff, P., Wease, S., Peled, A., Snyder, D., Cohen, E. G., Shoham, H., Landau, E., Friend, E., Peleg, I., Aschengrau, D., Yackoubov, D., Kurtzberg, J., \& Peled, T. (2014). Umbilical cord blood expansion with nicotinamide provides long-term multilineage engraftment. Journal of Clinical Investigation, 124(7), 3121-3128.

79. Ratajczak, J., Wysoczynski, M., Zuba-Surma, E., Wan, W., Kucia, M., Yoder, M. C., \& Ratajczak, M. Z. (2011). Adult murine bone marrow-derived very small embryonic-like stem cells differentiate into the hematopoietic lineage after coculture over OP9 stromal cells. Experimental Hematology, 39(2), 225-237.

80. Ratajczak, J., Zuba-Surma, E., Klich, I., Liu, R., Wysoczynski, M., Greco, N., Kucia, M., Laughlin, M. J., \& Ratajczak, M. Z. (2011). Hematopoietic differentiation of umbilical cord blood-derived very small embryonic/epiblast-like stem cells. Leukemia, 25(8), 12781285.

81. Ganguly, R., Metkari, S., \& Bhartiya, D. (2018). Dynamics of bone marrow VSELs and HSCs in response to treatment with gonadotropin and steroid hormones, during pregnancy and evidence to support their asymmetric/symmetric cell divisions. Stem Cell Reviews and Reports, 14(1), 110-124.

82. Blau, H. M., \& Daley, G. Q. (2019). Stem cells in the treatment of disease. The New England Journal of Medicine, 380(18), 17481760.

83. Yoshihara, M., Hayashizaki, Y., \& Murakawa, Y. (2017). Genomic instability of iPSCs: Challenges towards their clinical applications. Stem Cell Reviews and Reports, 13(1), 7-16.

84. Kumar, S., \& Geiger, H. (2017). HSC niche biology and HSC expansion ex vivo. Trends in Molecular Medicine, 23(9), 799-819.

85. Koldej, R., Collins, J., \& Ritchie, D. (2018). P2X7 polymorphisms and stem cell mobilisation. Leukemia, 32(12), 2724-2726.

86. Capitano, M. L., Hangoc, G., Cooper, S., \& Broxmeyer, H. E. (2015). Mild heat treatment primes human CD34(+) cord blood cells for migration toward SDF-1alpha and enhances engraftment in an NSG mouse model. Stem Cells, 33, 1975-1984.

87. Huang, X., Lee, M. R., Cooper, S., Hangoc, G., Hong, K. S., Chung, H. M., \& Broxmeyer, H. E. (2016). Activation of OCT4 enhances ex-vivo expansion of human cord blood hematopoietic stem and progenitor cells by regulating HOXB4 expression. Leukemia, 30(1), 144-153.

88. Forristal, C. E., Winkler, I. G., Nowlan, B., Barbier, V., Walkinshaw, G., \& Levesque, J. P. (2013). Pharmacologic stabilization of HIF-1alpha increases hematopoietic stem cell quiescence in-vivo and accelerates blood recovery after severe irradiation. Blood, 121(5), 759-769.

89. Wu, W., Kim, C. H., Liu, R., Kucia, M., Marlicz, W., Greco, N., Ratajczak, J., Laughlin, M. J., \& Ratajczak, M. Z. (2012). The bone marrow-expressed antimicrobial cationic peptide LL-37 enhances the responsiveness of hematopoietic stem progenitor cells to an SDF-1 gradient and accelerates their engraftment after transplantation. Leukemia, 26(4), 736-745.

90. Ratajczak, M. Z., \& Adamiak, M. (2015). Membrane lipid rafts, master regulators of hematopoietic stem cell retention in bone marrow and their trafficking. Leukemia, 29(7), 1452-1457.

91. Hoggatt, J., Singh, P., Sampath, J., \& Pelus, L. M. (2009). Prostaglandin E2 enhances hematopoietic stem cell homing, survival, and proliferation. Blood, 113(22), 5444-5455.

92. Ratajczak, M. Z., \& Suszynska, M. (2016). Emerging strategies to enhance homing and engraftment of hematopoietic stem cells. Stem Cell Reviews and Reports, 12(1), 121-128.

93. Adamiak, M., Moore, J. B., 4th, Zhao, J., Abdelbaset-Ismail, A., Grubczak, K., Rzeszotek, S., Wysoczynski, M., \& Ratajczak, M. Z. (2016). Downregulation of Heme oxygenase 1 (HO-1) activity in hematopoietic cells enhances their engraftment after transplantation. Cell Transplantation, 25(7), 1265-1276.

Publisher's Note Springer Nature remains neutral with regard to jurisdictional claims in published maps and institutional affiliations. 